DOI 10.37882/2223-2982.2020.09.21

\title{
ОСОБЕННОСТИ АДРЕСАНТ-АДРЕСАТНЫХ ОТНОШЕНИЙ КАК РЕЗУЛЬТАТА ИНТЕРАКЦИИ В ПРОТЕСТАНТСКОМ ДИСКУРСЕ (НА МАТЕРИАЛАХ ПЕРМСКОЙ И СВЕРДЛОВСКОЙ ОБЛАСТЕЙ СОВЕТСКОГО ПЕРИОДА)
}

\section{THE ADDRESSEE-ADDRESSEE COMMUNICATION AS A RESULT OF INTERACTION IN THE PROTESTANT DISCOURSE (BASED ON THE MATERIALS OF THE PERM AND SVERDLOVSK REGIONS OF THE SOVIET PERIOD)}

Yu. Moskvina

Summary: The article is a fragment of linguistic analysis of Protestant discourse materials conducted on three levels: morphological, lexicalsemantic, and syntactic. The object of research was materials is based on materials devoted to the activities of unregistered fraternities in the Perm (Molotov) and Sverdlovsk regions in the period from 1944 to 1964. This period was characterized by serious persecution of various religious cults, which predetermined the nature of interaction. It has been revealed that the addressee uses a wide range of specific language units (archaisms, sovietisms, bibleisms, historisms, etc.) that are widespread for Protestant discourse.

Keywords: religious discourse, interaction, Protestant discourse, speech influence, linguistic analysis.
Д искурс является коммуникативным событием, которое проявляет природу интерактивности через совокупность языковых составляющих, сых с когнитивными процессами в сознании коммуникантов. На когнитивные процессы, в свою очередь, оказывает влияние внеязыковая информация - знания коммуникантов о мире. Любая коммуникация подразумевает интеракцию между, как минимум, двумя сторонами. Коммуникантами оказываются объектами любого рода и происхождения, которые складываются в единообразную онтологическую категорию «адресант-адресат». Известно, что любая коммуникация - это процесс, в котором задействованы как минимум два действующих лица - адресант и адресат. Дискурсивный анализ направлен на фиксацию разнообразных коммуникативных действий, что даёт возможность определить и описать множество сценариев как фиксированных отношений между субъектами речи в типичных ситуациях общения.

Под религиозным дискурсом мы понимаем регламен-

\author{
Москвина Юлия Александровна \\ Преподаватель, Уральский государственный \\ университет путей сообщения (Екатеринбург) \\ moskvina_yuliya@bk.ru
}

Аннотация: (татья представляет собой фрагмент лингвистического анализа материалов протестантского дискурса, проведенного на трех уровнях: морфологическом, лексико-семантическом, синтаксическом. 0бъектом исследования послужили материалы, посвященные деятельности незарегистрированных братств на территории Пермской (Молотовской) и Свердловской областей в период с 1944 по 1964 гг. Этот период характеризовался серьезными гонениями на различные религиозные культы, что предопределило характер интеракции. Выявлено применение адресантом широкого ряда специфических языковых единиц (архаизмов, советизмов, библеизмов, историзмов и т.д.), свойственных протестантскому дискурсу.

Ключевые слова: религиозный дискурс, интеракция, протестантский дискурс, речевое воздействие, лингвистический анализ.

тируемую определенными историческими и социокультурными кодами (традициями) смыслообразующую и смысловоспроизводящую деятельность, направленную на формирование, трансляцию и изменение догматического мышления, сакрального мироощущения и мистического опыта [7, с. 32]. Религиозный дискурс будет всегда определяться и экстралингвистическими факторами: особенности конфессии, взаимоотношения с государственными структурами, социальный и национальный состав верующих и др.). На особенности религиозного дискурса могут оказывать влияние роли отправителя информации и получателя. Достижение цели коммуникативных намерений определяет как организация языковых средств воздействия, так и сущность адресата. Если адресантом в нашем исследовании являются представители протестантских организаций (рядовые верующие, пресвитеры, старшие пресвитеры), то адресатом послания могут выступать совершенно разные группы лиц, что будет определять выбор способа воздействия на сознание адресата. По мнению американских право- 
славных богословов Ч.С. Эванса и Р.З. Мэниса, «религиозный человек не просто отличается иными чувствами, установками или даже действиями. Он мыслит иначе о себе и своем мире» [3, с. 15].

Руководствуясь двумя критериями, нами выделено два вида протестантского дискурса:

1. социальные (экстралингвистические) критерии. В данном случае социальная среда накладывает роли на адресанта-адресата. При этом роль адресанта первична, поскольку его роль формирует роль адресата.

2. лингвистические (интралингвистические) критерии. В данном случае, после того, как роли прописаны, формируются речевые стратегии адресанта.

Религия оказывается не столь начальным адресантом, но адресантом-медиумом (проводником) между высшими силами и прихожанами. В определенные эпохи адресаты меняются. В результате этого возникает особая категория религиозного дискурса, который представляет собой свод религиозных сообщений или посланий. В рамках первой интеракции «религия-верующий человек» (первый подвид протестантского дискурса) человек верующий не осуждает и не сомневается в сообщениях адресанта, поскольку адресант и адресат разделяют одну систему ценностей и моральных установок. Такой дискурс справедлив и для советского периода, так как на него не оказывают влияние эксталингвистические факторы. Подобный дискурс является закрытым. Религиозные послания остаются неизменными с течением времени, следуя основным религиозным принципам: каноничности и консерватизму.

Интенция же адресанта во второй группе коммуникантов «верующий - неверующий» (второй подвид протестантского дискурса) - внушение отличных от позиций адресата взглядов, и все речевые средства подчинены этой интенции. Нередко этот вид дискурса менялся в зависимости от экстралингвистических факторов, т.е. является открытым. Необходимо отметить, что если отношение представлять на оси терпимости, то иллокутивная сила будет устремлять эти виды дискурса в сторону минуса или в сторону плюса, но никогда этот дискурс не будет иметь нулевое значение (эмоционально нейтральным).

Ярким примером религиозного дискурса как способа интеракции являются материалы, посвященные деятельности незарегистрированных братств на территории Пермской (Молотовской) и Свердловской областей в период с 1944 по 1964 гг. Необходимо отметить, что данный период характеризовался серьезными гонениями на различные религиозные культы, что предопределило характер интеракции.
На отрицательный характер интеракции повлияла структура самого братства. Поскольку непосредственным адресантом является пресвитер, глава протестантской общины, интерпретация событий вне общины зависела от его опыта. Пресвитер зачастую являлся единственным связующим звеном между верующими и центральным органом управления делами конфессии (например, Всесоюзным советом евангельских христиан-баптистов), верующими и областным правительством Совета по делам религиозных культов СССР, верующими и журналистами. Пресвитеру требовалось транслировать сакральные знания без смысловых искажений, которые могли бы повлечь за появление ереси или раскола.

На характер интеракции оказывал влияние и статус общины. Часть конфессий, прошедших регистрацию в областных представительствах Совета по делам религиозных культов СССР, получила покровительство властей, но на незарегистрированные общины были открыты гонения. Именно поэтому риторика взаимодействия органов власти с различными конфессиями будет разной. Регистрацию могли получить лишь те общины, которые отказывались от ключевых ценностей протестантизма: религиозное обучение детей, всеобщее миссионерство, пацифизм. Адресата характеризует и индивидуальное восприятие религиозного опыта. Говорение на языках пятидесятников, религиозные «откровения» баптистов и меннонитов закреплены через систему зафиксированных высказываний как в устной, так и в письменной форме. Религиозный догматизм характерен для речемыслительной деятельности пресвитера, что находит свое отражение и в тексте материалов различных жанров. Картина мира каждого верующего будет определять его общение с внешним миром.

Соответственно, исследуя различные материалы, посвященные жизни протестантских общин в период 19441964 гг., внутри дискурса «верующий - неверующий» можно выделить: 1) верующий - атеист (обращенные к неверующим послания в нелегальных религиозных печатных изданиях и статьи-интервью в официальных периодических изданиях); 2) верующий - уполномоченный государственной власти (протоколы с официальных судебных заседаний, протоколы товарищеских судов по месту работы верующих, протоколы «воспитательных» бесед, жалоб, обращений и протестов верующих в официальные органы); 3) верующий - верующий другой конфессии (протоколы заседаний советов верующих периода раскола внутри ВСЕХБ). Для адресанта последней группы представитель другой конфессии (адресат) также будет считаться «отступником», «неверным», «иноверцем». Всего в рамках данной статьи проанализировано шесть документов различных жанров. Материалы позволяют сделать вывод, что иллокутивная сила этого подвида имеет отрицательный вектор. 
Лингвистический анализ вышеуказанных материалов был проведен на трех уровнях: морфологическом, лексико-семантическом, синтаксическом. Результаты анализа указывают на отрицательный характер интеракции, из чего складывается и конфликтность данных дискурсов.

На морфологическом уровне для протестантского дискурса свойственен префиксально-постфиксальный способ словообразования, которым пользуются большинство верующих в качестве разговорной лексики: озлобиться, выругаться, вынарядиться, рабатывать.

Конверсия, или морфолого-синтаксический способ, представлена в 125 употреблениях: верующий в Бога (причастие), собрание верующих (подлежащее), причащзаюшиеся, молящиеся, исповедующиеся, сопротивляющиеся. Статистика показывает, что конверсия широко распространена в исследуемом материале, Изученные тексты обладают большей пресуппозитивной составляющей.

Протестантский, как и весь религиозный дискурс, отличается и словосложением (67 употреблений): богобоязненный, богоявленный, клятвоотступник, внутрицерковный, общецерковный, антиевангельский, противочерковный.

Лексический уровень любого вида дискурса представляет особый интерес для исследователя, поскольку именно здесь он обращает внимание на специфику применяемых лексических единиц. Каждый вид дискурса характеризуется особой лексикой, служащей для описания участников коммуникативной ситуации, их поступков и характеристик $[1$, с. 8]. Стоит отметить, что лексический уровень зависит от дискурса и будет разным при реализации той или иной интеракции. Рассмотрим лексический уровень интеракции «пресвитер - верующий». Здесь мы можем отметить два аспекта: лексико-грамматические трансформации и особая лексика. Поле особой лексики формируется за счет лексико-грамматических трансформаций, так и за счет архаизмов, аббревиатур, советизмов.

Характерными чертами интеракции (на лексическом уровне) адресанта - адресата в религиозном дискурсе вступают консервативность и каноничность, что сближает дискурс небольших поместных общин и крупных церковных сообществ. Несмотря на то, что протестантизм - одно из самых молодых направлений христианства, протестантскому дискурсу свойственно большое количество архаизмов, библеизмов и историзмов. С другой стороны, на лексический уровень интеракции пресвитера оказывал влияние и существовавший политико-экономический строй, что объясняет появление в дискурсе советизмов.
Историзмы представлены двумя группами:

1. социальные явления советского строя (10 употреблений) - октябрята, пионеры, воронаевцы, («Наши дети не могут быть октябрятами и пионерами, мы - христиане» [15]. («...которая состояла с очень давнего времени в секте пятидесятниковворонаевцев» [7];

2. наименование органов государственной власти (25 употреблений) - Совет по делам религиозных культов, Отдел по делам религиозных культов («Нам поручено сказать вам, что председатель Совета по делам религиозных культов при Совете Министров СССР...») [12].

Стоит отметить, что лексико-словообразовательные советизмы встречаются восемь раз: колхозники, агитработа.

Архаизмы представлены тремя группами:

1. наименование характеристик человека, всего 10 употреблений - ратобореи, ропотник, самочинные, радивые [17]. («Стыдно за ратоборцев, за съезд, что они оказались способными на такие самочинные действия») [12];

2. объекты окружающей действительности, 23 употреблений - казна, черьковь («Церьковь ЕХБ под руководством Оргкомитета в течение двух лет...») [14];

3. абстрактные понятия, 13 употреблений - наречие ( в знач. язык: «...говорение» на непонятном языке будто бы являющимся «английским наречием» [13], служенье, грамота (в знач. читать и писать). В исследуемых материалах библеизмы встречаются крайне редко, что можно объяснить, прежде всего, принадлежностью их к официально-деловому стилю.

Обнаруженные библеизмы относятся к новозаветизмам и подразделяются, в соответствии с классификацией Л.Г. Лунновой [10], на следующие группы:

1. глагольные,

2. употребления (просить Христа ради);

3. наречные, 3 употребления (с миром, всем сердчем);

4. междометные, 1 употребление (Христа ради). «... проповедник благоговейно закроет Евангелие и призовет Христа ради братьев» [2].

Отсутствие среднего образования, социальный статус как верующих, так и самих уполномоченных объясняет широкое применение просторечий и разговорной лексики в официальных документах. Всего находим 60 употреблений: чинить, хребет, надумать, озлобиться, выругаться, потворствовать, рядиться («- Bсе pоnщешь, брат? - А ты, сестра, все в платье благочестия рядишься?», «Никогда нигде не рабатывала, перебивалась 
выручкой от базарной толкучки») [2]. Распространенность просторечий и разговорной лексики характерна зачастую для жалоб, протестов верующих в официальные органы власти. Как показывают результат исследования, дискурс второго вида представляет собой совокупность интеракций «верующий-правоохранительные органы в лице уполномоченного по делам религиозных культов СССР». В данном случае интеракция является отрицательной за счет использования слов с негативной семантикой.

В группе коммуникантов «верующий-уполномоченный государственной власти», можно выделить несколько способов выражения негативного отношения представителей советской власти к верующим. К первому способу следует отнести применение лексики с ярко выраженной негативной окраской (35 употреблений). Все языковые единицы могут быть расклассифицированы следующим образом:

1. зооморфизмы (паразит);

2. социальные группы (тунеядец, проходимец).

«Статьей четвертой упомянутого Указа предусмотрено, что если при проверке и рассмотрении материалов о лице, ведущем паразитический образ жизни, в его действиях будут установлены признаки уголовного преступления...» [14]. В данном случае представитель органов выражает бесполезность (обременительность) верующих для общества. Несмотря на то, что сами верующие свою общину сектой не считали - «... ни в одном Евангелие нет названия «секта»), они, по настоянию уполномоченных использовали ту же негативно окрашенную лексику. «Вы знакомы с тем, что ваша секта запрещена законом?» [16].

Второй способ, по Е.А. Кожемякину, подразумевает применение нейтральной лексики (32 употребления), которая содержит в себе сему (не) отрицательной оценки: нерадивый, нелегальный, незарегистрированный. В изученных материалах обнаружены и языковые единицы, сниженность которых позволяет выявить третий способ выражения отрицательного отношения с помощью лексических средств (9 употреблений): потворствовать, зажимать. Синтаксический уровень анализа показывает, что, несмотря на желание адресанта больше влиять на адресата при помощи тактик, он может использовать только ограничительный объем языковых средств, присущих конкретному языку. Адресант не может выйти за рамки обычного синтаксиса и допустить синтаксические ошибки, поскольку иначе он будет неверно воспринят адресатом.

Группе коммуникантов «верующий - неверующий» при тактическом выборе средств задействуются отношения «свой - чужой». В данной категории можно выделить два подвида: «верующий - неверующий, предста- витель другой конфессии», «верующий - представитель органов власти». Первый подвид «верующий - неверующий» формирует роль неверующего под влиянием роли адресанта, т.е. даже если он верит в Бога, то в глазах протестантов одной конфессии, он отступник от догматов именно этого братства. «Чужой» в глазах верующего не только неправ в поступках, но и склонен ко лжи. Именно поэтому зачастую верующие используют манипулятивные приемы с целью внушения определенных взглядов.

Речевое манипулирование в данных дискурсах предстает как скрытое воздействие на сознание реципиента в пользу говорящего, или, как отмечает О.Н. Завьялова, «вид речевого воздействия, используемый для скрытого внедрения в психику адресата целей, желаний, намерений, отношений или установок, не совпадающих с теми, которые имеются у адресата в данный момент» [6]. При реализации тактических установок, в данных дискурсах, разворачиваются две темы:

1. высказывания, вольно интерпретирующие Писание;

2. высказывания - призывы.

Высказывания, вольно интерпретирующие Писание позволяют преподносить субъективную точку зрения в качестве «исходной очевидности» (12 употреблений). Данный вид высказываний отмечен в группе коммуникантов «верующий-представитель органов».

Н.Д. Голевым был предложен такой определяющий признак манипуляции, как ложь, что соответствует некоторым сложившимся научным представлениям [5, с.10].

При цитировании слов человека (в данном случае, Писания), являющегося авторитетом для адресата, или при упоминании авторитетного имени в манипулятивном тексте цитата зачастую вырывается из общего контекста и домысливается или объясняется манипулятором таким образом, будто авторитет поддерживает взгляды манипулятора или одобряет действия, к которым тот призывает [8, с. 124; 19, с. 692]. В данном случае интеракция формируется В следующий тактический прием, который отражают синтаксические конструкции: «я знаю..., я думаю..., я уверен». Далее адресант неверно цитирует авторитетный источник (Библию).

Ярким примером служит выдержка из Протокола общественного суда над А.Е. Меньшиковым, верующим ЕХБ: «Я знаю, что бог посылает царей, а они всем руководят...» [16]. Эта выдержка иллюстрирует основной принцип, которым руководствовались зарегистрированные протестантские общины в советский период: «Нет власти не от Бога». В Библии же находим следующее. Бог а) сам ставит царей над народами: Всевышний владычествует над чарством человеческим и дает его, кому хочет (Дан. 4:22,29; срав. Сир. 10:4); низлагает чарей и 
поставляет царей (Дан. 2:21) каждому народу поставил Он вождя (Сир. 17:14; срав. Прем. 6:1-3); б) сам же, наконец, и управляет через царей земными царствами: Мною цари царствуют и повелители узаконяют правду (Прит. 8:15). Сердие царя - в руке Господа, как потоки вод: куда захочет, Он направляет его (Прит. 21:1). Таким образом, по словам А.Е. Меньшикова руководят «цари» самостоятельно, однако в Библии сказано, что Бог управляет сам через «царей». Объяснить данную интерпретацию Библии следует политическими реалиями того периода, когда преследовали верующих, ставящих под сомнение саму природу советской власти.

В высказываниях-призывах присутствуют формы повелительного наклонения глагола и другие средства, которые способны выступать в функции побуждения (инфинитив, интонационные конструкции) [3,с. 127]. Использование призыва исследовал в своих работах М.А. Осадчий. Он считает свидетельством наличия призыва в тексте реализацию полной или сокращенной схемы призыва: наименование адресата - наименование действия - наименование объекта - императив.

Базовая языковая единица, обладающая призывной (императивной) семантикой, - это глагол. Основной, а значит самой яркой и очевидной его формой для выражения воления является форма второго лица повелительного наклонения единственного и множественного числа: иди (идите), ешь (ешьте) и т.п.

К.И. Бринев, выделял призывы определенные и неопределенные. В определенных призывах, к которым относятся протест верующих, желаемые действия властей конкретизируются. Структура определенных призывов будет выглядеть, вероятно, следующим образом: А) Хочу, чтобы было X Б) Знаю, что X не может произойти само В) Знаю, что если делать У, то, возможно, что будет $X$ Д) Знаю, что если буду говорить тебе, что необходимо, чтобы было X, возможно, что ты будешь делать так, чтобы было X E) Знаю, что если буду говорить тебе, что нужно делать, чтобы было X, возможно, ты будешь делать то, что говорю тебе, и наступит Х. Ж) Говорю тебе: необходимо, чтобы было X 3) Говорю тебе: делай У И) Говорю это тебе для того, чтобы ты делал так, чтобы было X [4, с.137].

В исследуемых материалах высказывания-призывы отмечены в протестах, жалобах верующих и в протоколах заседаний ВСЕХБ и СЦ ЕХБ, всего 8 реализаций. Примером можем назвать следующий протест верующих ВСЕХБ: «Если вы с нами не соглашаетесь, что мы у вас как рабы в угнетении, то предоставьте нам отобранные молитвенные дома, разрешите свободное печатание нашей духовной литературы...» [15]. Приведенный отрывок можно отнести к финальным элементам структуры определенного призыва. Проведенный лингвистический анализ вышеуказанных материалов на морфологическом, лексико-семантическом и синтаксическом уровнях показал применение адресантом широкого ряда специфических языковых единиц (архаизмов, советизмов, библеизмов, историзмов и т.д.), свойственных протестантскому дискурсу. Применение манипулятивных речевых стратегий служит реализации коммуникативной цели адресанта - внушения определенных взглядов и позиций адресанту.

\section{ЛИТЕРАТУРА}

1. Dijk T.A. van. News as Discourse. N. Jersey; London: Lawrence erlbaum associates, 1998. 200 p.

2. Астраханцев И. Тайны молитвенного дома // Тавдинская правда. 1981. 10 января.

3. Баранов А.Н. Лингвистическая экспертиза текста: теория и практика: учеб. пособие. М.: Флинта, 2007. 592 с.

4. Бринев К.И. Теоретическая лингвистика и судебная лингвистическая экспертиза: монография. Барнаул: Изд-во Алтайской государственной педагогической академии, 2009.252 с.

5. Голев Н.Д. Суггестивное функционирование внутренней формы слова в аспекте ее взаимоотношений с языковым сознанием // Языковые единицы в семантическом и лексикографическом аспектах / Под ред. Н.А. Лукьяновой. Новосибирск: Новосибирский университет, 1998. С. 9-20.

6. Завьялова 0.Н. Речевое (языковое) манипулирование // Культура русской речи. Энциклопедический словарь-справочник / Под рук. Л.Ю. Иванова, А.П. Сковородникова, Е.Н. Ширяева. М.: Флинта, 2003. С. 566-570.

7. Кожемякин Е.А. Дискурсный подход к изучению институциональной культуры. Белгород: БелГУ, 2008. 246 с.

8. Кара-Мурза С.Г. Манипуляция сознанием. М.: Алгоритм, 2004. 526 с.

9. Кожемякин Е.А. Религиозный дискурс: методология исследования // Научные ведомости Белгородского государственного университета. 2011. № 2 (97). C. $32-47$.

10. Луннова М.Г. Библеизмы в современном русском языке // Известия Пензенского государственного педагогического университета им. В.Г. Белинского. 2008. № 13. С. $40 \neg 45$.

11. Осадчий М.А. Классификация методов судебной лингвистической экспертизы (на материале экспертной оценки призыва) // Современные проблемы науки и образования. 2011. № 6. С. 3.

12. [Письмо поместным церквям] // Архив Российского союза евангельских христиан-баптистов. Документ 32-28.

13. Письмо Опунина И.А. // Государственный архив Пермского края (ГАПК). Р-1204. Оп 1. Ед. хр. 10. Л. 85. 
14. Протест верующих евангельско-баптистского исповедания Урала // ГАПК. Р-1204. Оп 1. Ед. хр. 8. Л. 228.

15. Протест верующих города Перми и Краснокамска // ГАПК. Р-1204. Оп. 1. Ед. хр. 8. Л. 335-336.

16. Протокол допроса Меньшикова А.Е. // ГАПК. Р-1204. Оп 1. Ед. хр. 10. Л. 41.

17. Словарь русского языка: в 4-х т. / Ин-т лингвистич. Исследований РАН; Под ред. А. П. Евгеньевой. 4-е изд., стер. М.: Русский язык; Полиграфресурсы, 1999.

18. Совет церквей евангельских христиан-баптистов // Братский листок. 1970. № 5. С. 23.

19. Шейнов В.П. Скрытое управление человеком (Психология манипулирования). Минск: Харвест, 2004. 816 с.

20. Эванс Ч.С., Мэнис Р.З. Философия религии: размышления о вере / пер. с англ. Д.Ю. Кралечкина. М.: Изд-во ПСТгУ, 2011. 232 с.

○ Москвина Юлия Александровна (moskvina_yuliya@bk.ru)

Журнал «Современная наука: актуальные проблемы теории и практики»

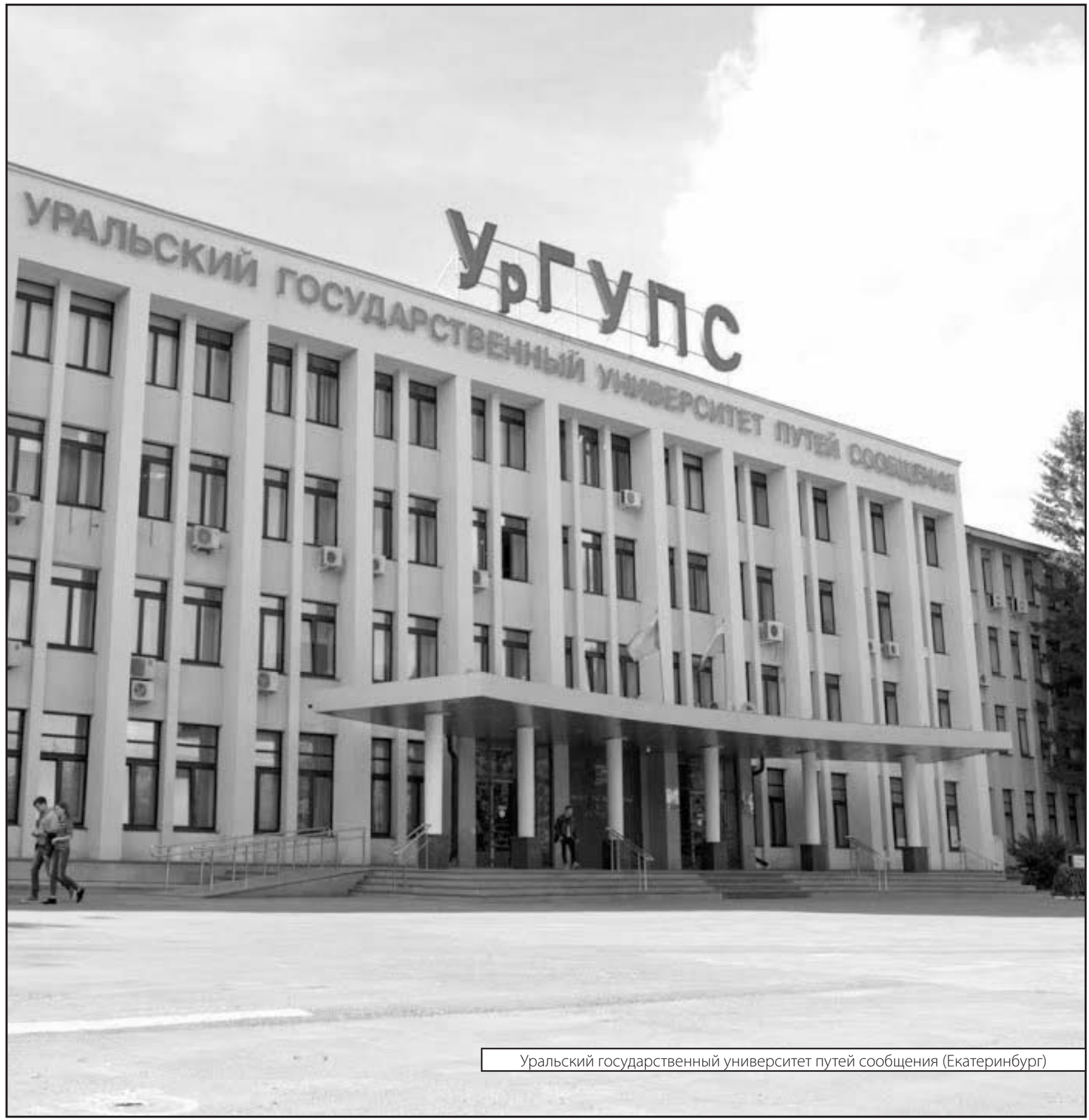

